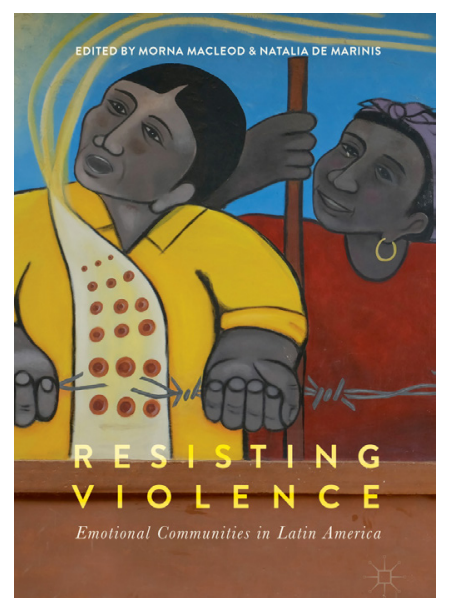

- Resisting Violence. Emotional Communities

in Latin America

Morna MACLEOd Y NATALIA de MARINIS (EDS.), 2018

Palgrave Macmillan, Nueva York.

\title{
Pensar de manera apasionada: comunidades emocionales y resistencia política en contextos de violencia en Latinoamérica
}

\author{
DIANA ALEJANDRA SILVA LONDOÑO
}

Thinking Passionately: Emotional Communities and Political Resistance in Violent Contexts of Latin America

Diana Alejandra Silva Londoño

Universidad Autónoma Metropolitana, Unidad Iztapalapa, Ciudad de México, México diana.alejandra.silva@gmail.com

Desacatos 63, mayo-agosto 2020, pp. 162-166

ste libro colectivo nos ofrece una mirada novedosa para conocer desde la emoción y pensar de manera apasionada fenómenos sociales de gran relevancia, como las luchas por la memoria y la construcción del testimonio, que ya cuentan con una amplia tradición en Latinoamérica. Con un enfoque que recupera la centralidad de las emociones para comprender los procesos políticos locales de resistencia a la violencia que aqueja a la región, se constituye en una excelente contribución que busca distanciarse de las falsas dicotomías entre emoción y razón tan presentes en las ciencias sociales.

Como eje para la discusión colectiva, se retoma el concepto de comunidades emocionales, acuñado por la antropóloga colombiana Miriam Jimeno y sus colaboradores, quienes participan en este libro con el capítulo "Violence, Emotional Communities, and Political Action in Colombia". Como se señala en el estudio introductorio de este volumen, realizado por las editoras, el concepto de comunidades 
emocionales surge como resultado del trabajo etnográfico de largo aliento de distintas investigaciones realizadas por Jimeno desde 1991, en diálogo con contribuciones que se han hecho en antropología para comprender las emociones desde el punto de vista sociocultural. Formulado de manera explícita y sistemática, este concepto aparece en los textos producidos por Jimeno y su equipo, a partir del proceso de acompañamiento a la comunidad Kitek Kiwe entre 2008 y 2014 (Jimeno, Varela y Castillo, 2015), la cual fue desplazada del Alto Naya y reasentada en el municipio de Timbío tras una brutal masacre cometida por grupos paramilitares del Bloque Calima (1999-2004) y el ejército colombiano (Centro Nacional de Memoria Histórica, 2018).

La potencia de este concepto es que, si bien permite indagar en torno a los acontecimientos violentos, también posibilita la comprensión de los procesos y mecanismos socioculturales que incidieron en la recomposición individual y colectiva de la población acompañada por Jimeno y su equipo. En este proceso de recomposición, desempeñó un papel central la construcción colectiva de una narrativa en las conmemoraciones anuales de la masacre, con la que se construye un testimonio colectivo de los acontecimientos violentos y también se alude al proceso de reconstrucción de la comunidad de Kitek Kiwe. En esta propuesta, las conmemoraciones se analizan como actos rituales o performáticos que posibilitan la construcción colectiva y pública del testimonio, por medio de las cuales se ejercen las reivindicaciones políticas de la comunidad en la búsqueda de verdad, justicia, reparación integral y garantías de no repetición. En este sentido, este concepto es una apuesta política por dignificar las experiencias de resistencia sin caer en una sobrerrepresentación de la figura de la víctima y sin minimizar los acontecimientos violentos vividos (Jimeno y Macleod, 2014).

En este sentido, es un concepto que permite comprender los vínculos entre las emociones, los afectos y la acción política, así como los vínculos que se producen entre las víctimas sobrevivientes con un público más amplio, que escucha los testimonios y pueden construirse alianzas, como sucede con funcionarios gubernamentales, activistas, voluntarios, defensores de derechos humanos, miembros de las organizaciones comunitarias y los propios investigadores que acompañan y participan en estos procesos. De este modo, el testimonio no sólo se entiende como aquel que se expresa en forma discursiva sino que incluye los distintos elementos rituales y performáticos en los cuales las emociones y el cuerpo ocupan un lugar central.

Lo anterior tiene repercusiones metodológicas sobre las que es preciso reflexionar. Por un lado, el desafío de reconocer, no sólo el discurso hablado, sino también los modos en los que la emoción se expresa por medio del cuerpo y las acciones, con elementos rituales y performáticos. Por el otro, también implica reconocer las emociones de los investigadores como parte del proceso de construcción de conocimiento y constitutiva de las relaciones que se construyen durante el trabajo de campo. Esto requiere un proceso de desaprendizaje que nos permita considerar las emociones como una vía de conocimiento y no como un obstáculo al principio de neutralidad que se promueve desde perspectivas positivistas. En todos los capítulos se reflexiona sobre las relaciones entre la actividad académica y los procesos políticos. Se propone una amplia diversidad de enfoques, entre los cuales cabe mencionar el acompañamiento, el conocimiento situado, la investigación-acción feminista participativa, la sistematización colaborativa y la investigación colaborativa.

Los capítulos que componen este volumen, si bien toman como punto de partida el concepto de comunidades emocionales, dan un paso más allá al introducir matices, variaciones, críticas y reflexiones metodológicas que permiten comprender otros procesos políticos con historias, lugares, actores y 
expresiones de violencias diferenciadas. De esta manera, encontramos trabajos que se fundamentan en las experiencias violentas acaecidas en las dictaduras del Cono Sur y los conflictos armados, con otras experiencias en las que la violencia política convive con la violencia resultante de la aplicación de las políticas neoliberales y la presencia creciente del crimen organizado.

En el capítulo "Testimony, Social Memory, and Stratregic Emotional/Political Communities en Elena Poniatowska's Crónicas”, de Lynn Stephen, se acuña el concepto de comunidades políticas emocionales estratégicas para pensar en aquellas comunidades emocionales en las que se vinculan distintas temporalidades y memorias de distintos acontecimientos. Para ello, se hace una revisión de las crónicas del terremoto de 1985 del libro Nada, nadie: las voces del temblor, de Elena Poniatowska, para comprender su influencia en las conmemoraciones del 30 aniversario, momento en el cual se relacionan las memorias del terremoto de 1985 con otros acontecimientos de gran impacto en el país, como la masacre de Tlatelolco de 1968 y la desaparición forzada de los estudiantes de Ayotzinapa en 2014.

Una reflexión similar, en relación con las distintas temporalidades presentes en los procesos de resistencia, ocurre en el capítulo "Protesting Against Torture in Pinochet's Chile: Movimiento Contra la Tortura Sebastián Acevedo”, de Morna Macleod, quien analiza la acción política del Comité Contra la Tortura Sebastián Acevedo, de Chile, ocurrida en plena dictadura militar. En las acciones del comité, fundamentadas en la acción performática, se produjeron comunidades emocionales que aparecían de forma momentánea y efímera con gran impacto en transeúntes anónimos.

En relación con la vinculación entre distintos espacios y tiempos, Angela Ixkic Bastian, en el capítulo "Emotions, Experiences, and Communities: The Return of the Guatemalan Refugees", expone la manera en la que se tejieron vínculos y emociones en torno a los refugiados guatemaltecos, quienes tras vivir 14 años en México retornaron a su país en el marco de la firma de los acuerdos de paz. En este capítulo se reconstruye dicho proceso al dar cuenta de la comunidad emocional resultante de actores sociales muy distintos entre sí. Por un lado, quienes sufrieron directamente la violencia, el desplazamiento forzado y el proceso de retorno, y por el otro, los observadores y acompañantes pertenecientes a las organizaciones no gubernamentales nacionales e internacionales. Bastian reflexiona sobre las relaciones de poder y jerarquía presentes en las comunidades emocionales, que pueden potenciar o limitar las posibilidades de escuchar y actuar de manera colectiva. En el caso estudiado, la existencia de relaciones de poder cruzadas por el colonialismo está presente en las relaciones entre los voluntarios acompañantes y las personas afectadas, pero también en la relación que establecemos como académicos.

Esta pregunta vuelve a abordarse en el capítulo "Affective Contestatios: Engaging Emotion through the Sepur Zarco Trial", de Alison Crosby, Brinton Likes y Fabienne Doiron, en el que se documenta el juicio de Sepur Zarco, en Guatemala, a partir de la acción protagónica de las mujeres q'eqchi', quienes, apoyadas por un conjunto de organizaciones sociales nacionales e internacionales con las que construyeron alianzas, y un grupo más amplio de mujeres mayas sobrevivientes de la violencia sexual, lograron que por primera vez en el mundo un tribunal nacional se pronunciara judicialmente sobre la esclavitud sexual en un conflicto armado. En este texto se muestra la presencia de múltiples comunidades emocionales compuestas por relaciones que siempre están en formación, disputa y tensión, y que incluyen las diferencias entre identidades, posiciones estructurales y experiencias como expresiones de las relaciones de poder. Este capítulo muestra cómo el acto de testimoniar no es neutral en términos de género, etnia, raza y clase social. Estos 
capítulos ofrecen una perspectiva crítica del concepto de comunidad emocional, y no sólo explican sus potencialidades sino sus desafíos.

En otros capítulos se enfatiza el carácter político de las comunidades emocionales, como ocurre en los trabajos de Natalia de Marinis, Jenny Pearce y Gisela Espinosa, quienes reconocen el papel de las emociones en la acción política que busca la construcción de la memoria, la verdad y la justicia. En "Political-Affective Intersections: Testimonial Traces among Forcibly Displaced Indigenous People of Oaxaca, México", Natalia de Marinis parte de la experiencia vivida con la población triqui desplazada de San Juan Copala en 2010. Una de las aportaciones de este estudio consiste en entender las emociones, no como categorías fijas, sino como flujos que circulan en las comunidades políticoemocionales, al evidenciar la cualidad humana de afectar y ser afectados por las emociones que traspasan los límites corporales y espaciales. Asimismo, nos muestra cómo la expresión pública de las emociones por parte de las mujeres triquis permitió la construcción de un nosotros, el cual posibilitó la dignificación de las narrativas colectivas en medio del dolor y la deshumanización provocada por la violencia y el desplazamiento forzado. Sin esta construcción de un nosotros atravesada por la expresión emocional en el espacio público, la acción política no hubiese podido tener lugar.

En "Emotional Histories: A Historiography of Resistances in Chalatenango, el Salvador", de Jenny Pearce, se recupera también este énfasis en la dimensión política de las comunidades emocionales. Pearce nos muestra cómo la politización del afecto se constituye en el puente que une la emoción con la resistencia, lo que permitió a los campesinos de Chalatenango hacer memoria, denunciar lo ocurrido y cuestionar la categoría de víctima con la que se les ha identificado, para reconocerse como sobrevivientes. En este trabajo se plantea la necesidad de excavar en las reservas de la memoria para reconstruir tanto una historiografía de las violencias vividas como de las resistencias colectivas, las cuales tienden a ser invisibilizadas pese a su importante papel en el cambio político y social.

A diferencia de los demás capítulos, en "Women Defending Women: Memories of Women Day Laborers and Emotional Communities", de Gisela Espinosa, se analizan las memorias y emociones que surgen de las violencias y la explotación cotidianas de un grupo de mujeres defensoras de los derechos humanos y jornaleras que participan en la organización Naxihi na xinxe naxihi - Mujeres en defensa de la mujer-, en San Quintín, Baja California. A partir de las movilizaciones de los jornaleros en 2015, por mejores condiciones de vida, se produce una comunidad político-emocional que posibilita la reflexión de las mujeres en torno a la migración, la maternidad, el trabajo en el campo y las dificultades para acceder a la educación y participar en el espacio público.

En todos los capítulos del libro, el concepto de comunidades emocionales, con sus distintos matices y aplicaciones, se constituye en una herramienta teórico-metodológica con la que se analizan aquellos procesos políticos en los que el testimonio y la acción performática tienen un lugar central y que son difícilmente explicados por el canon establecido en las teorías de los movimientos sociales (Tarrow, 1997; Melucci, 1991; Touraine, 1995). Por último, es necesario mencionar que si bien uno de los ejes de articulación del libro corresponde a una aplicación crítica del concepto de comunidades emocionales, hay también una amplia discusión en torno al papel del testimonio, la escucha, el silencio, la memoria y el olvido, que seguramente harán de este libro un importante referente de apoyo para los investigadores en la materia, así como para las actividades docentes, por la riqueza de las reflexiones de orden teórico, metodológico, axiológico y político. D 


\section{Bibliografía}

Centro Nacional de Memoria Histórica, 2018, Bloque Calima de las auc. Depredación paramilitar y narcotráfico en el suroccidente colombiano (informes sobre el origen y actuación de las agrupaciones paramilitares en las regiones, núm. 2), Centro Nacional de Memoria Histórica, Bogotá. Disponible en línea: <http://www.centrodememoriahistorica.gov.co/informes/informes-2018/bloque-calima-de-las-auc>. Jimeno, Myriam y Morna Macleod, 2014, Entrevista con Miriam Jimeno. Disponible en línea: <http://mornamacleod.net/?p=767>.

Jimeno, Myriam, Daniel Varela y Ángela Castillo, 2015, Después de la masacre: emociones y política en la Cauca media, Facultad de Ciencias Humanas-Universidad Nacional de Colombia-Sede Bogotá/Centro de Estudios Sociales, Instituto Colombiano de Antropología e Historia, Bogotá.

Melucci, Alberto, 1991, “La acción colectiva como construcción social”, Estudios Sociológicos, vol. 9, núm. 26, pp. 357-364.

Tarrow, Sidney, 1997, El poder en movimiento. Los movimientos sociales, la acción colectiva y la política, Alianza Editorial, Madrid.

Touraine, Alain, 1995, Producción de la sociedad, Universidad Nacional Autónoma de México-Instituto de Investigaciones Sociales, México. 